\title{
LIFE HISTORY AND VIABILITY OF A LONG-LIVED MARINE INVERTEBRATE: THE OCTOCORAL PARAMURICEA CLAVATA
}

\author{
Cristina Linares, ${ }^{1,2,6}$ Daniel F. Doak, ${ }^{3}$ Rafel Coma, ${ }^{1}$ David Díaz, ${ }^{4}$ and Mikel Zabala ${ }^{5}$ \\ ${ }^{1}$ Centre d'Estudis Avançats de Blanes, Accés Cala Sant Francesc 14, 17300 Blanes, Girona, Spain \\ ${ }^{2}$ Institut de Ciències del Mar, Passeig Maritim 37-49, 08003 Barcelona, Spain \\ ${ }^{3}$ Department of Ecology and Evolutionary Biology, University of California, Santa Cruz, California 95064 USA \\ ${ }^{4}$ Instituto Español de Oceanografía, C/ Moll de Ponent s/n, 07015 Palma de Mallorca, Spain \\ ${ }^{5}$ Departament d'Ecologia, Facultat de Biologia, Universitat de Barcelona, Avda Diagonal 645, 08028 Barcelona, Spain
}

\begin{abstract}
The red gorgonian Paramuricea clavata is a long-lived, slow-growing sessile invertebrate of ecological and conservation importance in the northwestern Mediterranean Sea. We develop a series of size-based matrix models for two Paramuricea clavata populations. These models were used to estimate basic life history traits for this species and to evaluate the viability of the red gorgonian populations we studied. As for many other slow-growing species, sensitivity and elasticity analysis demonstrate that gorgonian population growth is far more sensitive to changes in survival rates than to growth, shrinkage, or reproductive rates. The slow growth and low mortality of red gorgonians results in low damping ratios, indicating slow convergence to stable size structures (at least 50 years). The stable distributions predicted by the model did not differ from the observed ones. However, our simulations point out the fragility of this species, showing both populations in decline and high risk of extinction over moderate time horizons. These declines appear to be related to a recent increase in anthropogenic disturbances.

Relative to their life span, the values of recruitment elasticity for Paramuricea clavata are lower than those reported for other marine organisms but are similar to those reported for some long-lived plants. These values and the delayed age of sexual maturity, in combination with the longevity of the species, show a clear fecundity/mortality trade-off. Full demographic studies of sessile marine species are quite scarce but can provide insight into population dynamics and life history patterns for these difficult and under-studied species. While our work shows clear results for the red gorgonian, the variability in some of our estimates suggest that future work should include data collection over longer temporal and spatial scales to better understand the long-term effects of natural and anthropogenic disturbances on red gorgonian populations.
\end{abstract}

Key words: elasticity; gorgonian; life history; longevity; matrix models; Mediterranean; Paramuricea clavata; population viability analysis; recruitment; sensitivity; size-structured populations.

\section{INTRODUCTION}

While demographic models are widely used to assess the population viability and life history patterns of many terrestrial plant and animal species (Silvertown et al. 1996, Caswell 2001, Beissinger and McCullough 2002, Doak et al. 2002), they have been used less commonly in marine conservation than in other fields of population ecology (Crowder et al. 1994, Thompson et al. 2000, Holmes and York 2003, Gerber and Heppell 2004). In particular, age- or stage-based matrix models have been conducted on only a few groups of marine invertebrates, including sea urchins (Pfister and Bradbury 1996), bivalves (Nakaoka 1993, 1997), bryozoans (Hughes 1990), hard corals (Hughes 1984, Done 1988, Babcock 1991, Hughes and Tanner 2000), and soft corals and

Manuscript received 9 December 2005; revised 19 September 2006; accepted 29 September 2006. Corresponding Editor: S. R. Thorrold.

66-mail: clinares@ceab.csic.es gorgonians (Gotelli 1991, Lasker 1991, McFadden 1991).

In this study, we develop a demographic matrix model for populations of the long-lived, slow-growing Mediterranean red gorgonian coral, Paramuricea clavata (henceforth, red gorgonian). In common with other clonal plants and marine invertebrates (Hughes 1984, Cook 1985, Hughes and Jackson 1985), gorgonians have low recruitment rates, high longevity, and low mortality rates (Lasker 1991, Yoshioka 1994, Coma et al. 1998, 2003, 2004). These traits have resulted in local endangerment of red gorgonians by SCUBA-based tourism in marine reserves (Coma et al. 2004) and in regional endangerment due to mass mortality events (Cerrano et al. 2000, Perez et al. 2000, Linares et al. 2005). Red gorgonians and other long-lived species serve as "ecosystem engineers" (Jones et al. 1994) in Mediterranean marine hard-bottom communities, with significant effects on the structure and biodiversity of their communities. 


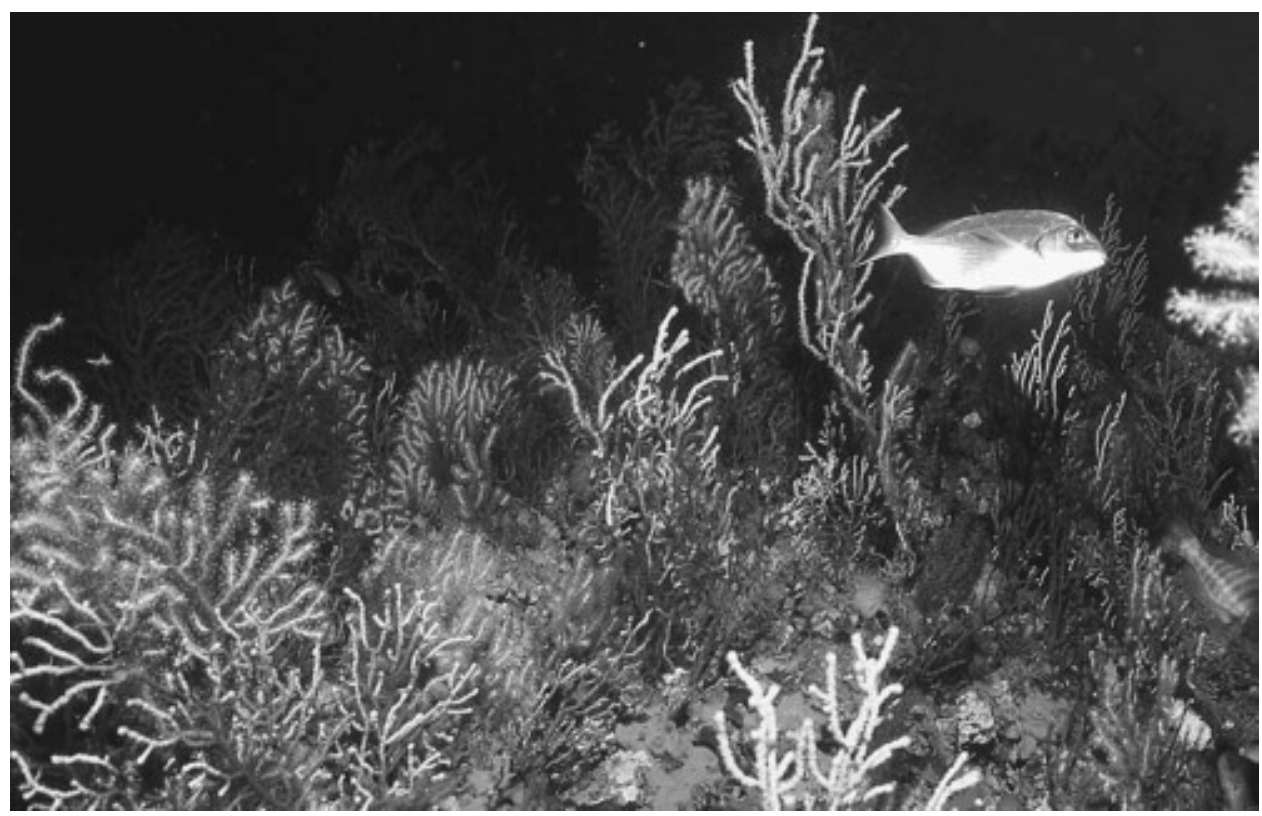

Plate 1. A red gorgonian (Paramuricea clavata) population in the Medes Islands (northwestern Mediterranean Sea). Photo credit: Enric Ballesteros.

We have developed both deterministic and stochastic size-based matrix models for two red gorgonian populations in the northwestern Mediterranean Sea. We use these models to address three goals. First, we estimate basic life history traits for this species and use the resulting models to evaluate the sensitivity of population growth to different vital rates. Second, we ask how population structure will develop through time and analyze the viability of the red gorgonian populations we studied. Third, we compare the life history patterns of red gorgonian to those of other sessile species of invertebrates and of terrestrial plants to highlight the significance of their reproductive strategy and the resemblance with species displaying similar life history traits despite having very different environments and evolutionary histories.

\section{Methods}

The natural history of Paramuricea clavata

Paramuricea clavata (Anthozoa, Octocorallia) is one of the key species of the highly diverse Mediterranean coralligenous communities, playing an important role in the maintenance of biomass and the structural complexity in these habitats (True 1970, Ballesteros 2006). Red gorgonians can be found in rocky substrates from $10 \mathrm{~m}$ to at least $110 \mathrm{~m}$, in locations subjected to strong currents (Weinberg 1991), and are widely distributed in the western basin of the Mediterranean and in the Adriatic Sea. In spite of the species' broad geographic range, red gorgonians have a strikingly patchy distribution (see Plate 1).

Red gorgonian colonies are discrete and generally assume a two-dimensional arborescent form, reaching heights of up to $1.5 \mathrm{~m}$. At present, there is no method available to directly estimate the age of living gorgonian colonies. Past studies have estimated mean growth rates of $\sim 0.8 \mathrm{~cm} / \mathrm{yr}$ in colony height (Coma et al. 2001; R. Coma, unpublished data), suggesting ages of up to 50 $100 \mathrm{yr}$ for individual colonies. However, breakage of branches on the main stalk is relatively common, so colonies may be much older than they appear. Due to variation in growth rates among individuals and the possibility that individuals can undergo "partial mortality" (loss of living tissue, in part due to branch breakage), two colonies of the same size may be very different in age. As for many other species with indeterminate growth, the demographic characteristics of gorgonian colonies (survival, growth, and fecundity) appear to be influenced more by size than by age. Consequently, we classify colonies by size in all of our models.

Gorgonians suffer high mortality rates as recruits and juvenile colonies (Coma et al. 2001) and low natural mortality as adults (Coma et al. 2004). While partial mortality due to strong currents occurs at a low rate, this damage can be dramatically increased by diving activity, fishing nets and lines, and mass mortality events (Bavestrello et al. 1997, Coma et al. 2004, Linares et al. 2005). Colonies can survive and potentially regrow following the loss of living tissue, but previous data indicate that regeneration depends on the extent of injuries and is often fairly low (Bavestrello and Boero 1986, Linares et al. 2005).

The reproductive biology of this species has been wellstudied. The red gorgonian is dioecious, with a sex ratio not significantly different from $1: 1$ in the studied 
TABLE 1. Size class transition matrix wherein matrix elements represent four types of variables $\left(f_{i}, g_{i}, h_{i}, h_{2 i}, s_{i}\right): f$, fecundity; $g$, growth; $h$, shrink into next smaller class; $h_{2}$, shrink into class two intervals smaller; $s$, survival.

\begin{tabular}{|c|c|c|c|c|c|}
\hline \multirow{2}{*}{$\begin{array}{c}\text { Size class } \\
t+1 \\
\end{array}$} & \multicolumn{5}{|c|}{ Size class at time $t$} \\
\hline & 1 & 2 & 3 & 4 & 5 \\
\hline 1 & 0 & 0 & 0 & $f_{4}$ & $f_{5}$ \\
\hline 2 & $s_{1} \times g_{1}$ & $s_{2} \times\left(1-g_{2}\right)$ & $s_{3} \times\left(1-g_{3}\right) \times h_{3}$ & 0 & 0 \\
\hline 3 & 0 & $s_{2} \times g_{2}$ & $s_{3} \times\left(1-g_{3}\right) \times\left(1-h_{3}\right)$ & $s_{4} \times\left(1-g_{4}\right) \times h_{4}$ & 0 \\
\hline 4 & 0 & 0 & $s_{3} \times g_{3}$ & $s_{4} \times\left(1-g_{4}\right) \times\left(1-h_{4}\right)$ & $s_{5} \times\left(1-g_{5}\right) \times h_{5}$ \\
\hline 5 & 0 & 0 & 0 & $s_{4} \times g_{4}$ & $s_{5} \times\left(1-g_{5}\right) \times\left(1-h_{5}\right)$ \\
\hline 6 & 0 & 0 & 0 & $0^{.4}$ & $s_{5} \times g_{5}$ \\
\hline 7 & 0 & 0 & 0 & 0 & 0 \\
\hline
\end{tabular}

Note: Two red gorgonian populations were studied in the northwestern Mediterranean Sea.

populations (Coma et al. 1995a; R. Coma, unpublished data). Spawning is synchronous and occurs twice each year in June around the new and full moons. Fertilization is external and embryogenesis takes place on the surface of the colony (Coma et al. 1995a). Red gorgonian planulae have little potential for dispersal and most settle near the parental colony (C. Linares, unpublished data). While red gorgonians make significant investment in reproduction each year, recruitment rates are typically low (Coma et al. 1995a, 2001).

\section{Data}

We analyzed the demographic parameters of red gorgonian populations located at two marine protected areas of the northwestern Mediterranean coast, Cap de Creus and Medes Islands, separated by $>25 \mathrm{~km}$. Both localities are typical of the habitats where well-developed red gorgonian populations are found along the northwestern Mediterranean coast, and the studied populations are located at the same depth range (15$25 \mathrm{~m}$ ). Due to their beauty, red gorgonian populations are among the most attractive areas for scuba divers, making it difficult to study populations that are not subjected to diving impacts. Although our study sites are located within marine reserves, both are subject to considerable levels of diving activity (Coma et al. 2004).

The demographic parameters used in this study are based on the data from a previous study (Coma et al. 2003), with survivorship, growth, and recruitment of red gorgonian colonies estimated from annual monitoring of six $4 \mathrm{~m}$ long and $0.8 \mathrm{~m}$ wide permanent plots at Cap de Creus (two plots from 2002-2004) and Medes Islands (four plots from 2001-2004). All colonies present in a plot were individually identified and mapped at the start of the study and relocated each year to record their fates. Each of the six plots contained between 80 and 200 colonies in each year of the study. The size of each colony was measured as maximum height in centimeters, and mortality was estimated both through the disappearance of whole colonies and by the presence of standing dead skeletons of colonies. Reproduction is extremely difficult to quantify in the field, so neither the sex nor reproductive effort was measured in this study. Previous work indicates that the size distributions and hence the demography of male and female colonies are similar (Coma et al. 2004). Newly settled primary polyps are extremely small and thus are not readily observable in the field, with newly found colonies typically between $0.3 \mathrm{~cm}$ and $\leq 3 \mathrm{~cm}$ height. Given the growth rates of newly settled individuals observed in the laboratory (C. Linares, unpublished data), these newly found colonies are likely to be in their second year of life.

\section{Model formulation}

We analyzed the demography of red gorgonians using a set of seven age- and size-defined stage classes. The first class is age-based, representing the "newborn" colonies (primary polyps) that we were unable to directly observe in the field. Class 2 colonies are at least $2 \mathrm{yr}$ old and between 0.3 and $3 \mathrm{~cm}$ in height, and we assumed that all newly observed colonies in the field fall into this class. The remaining colonies are all size-based: class 3 colonies are between 3 and $10 \mathrm{~cm}$ in height and are pre-reproductive, while classes 4 through 7 are 11-20 $\mathrm{cm}, 21-30 \mathrm{~cm}, 31-40 \mathrm{~cm}$, and $>40 \mathrm{~cm}$ in height, respectively, and have increasing reproductive output. These classes are chosen to match those used during previous work on this species (Coma et al. 1995b). Further division of the larger colonies into narrower size classes would be desirable, but the low numbers of colonies at these sizes prevent their use.

Across each annual transition period, each gorgonian colony could have one of five fates: (1) survive and grow to the next largest size class; (2) survive and shrink by one size class; (3) survive and shrink by two size classes (only applicable to classes 6 and 7); (4) survive but remain in the same size class; or (5) die. Because these overall fates are governed by combinations of survival, growth, and shrinkage rates, we performed most of our analysis on these underlying vital rates: $s_{i}$, the probability of a class $i$ colony surviving; $g_{i}$, the probability of a class $i$ colony growing (conditional on surviving); $h_{i}$, the probability of a class $i$ colony shrinking by either one or two size classes (conditional on surviving and not growing); and $h_{2 i}$, the probability of a class $i$ colony shrinking by two size classes (conditional on surviving and shrinking). The matrix model we used, defined in terms of these vital rates, is shown in Table 1. These rates were directly estimated from the data for each annual transition using all individuals in either popula- 
TABle 1. Extended.

\begin{tabular}{cc}
\hline \hline \multicolumn{2}{c}{ Size class at time $t$} \\
\hline 6 & 7 \\
\hline$f_{6}$ & $f_{7}$ \\
0 & 0 \\
0 & 0 \\
$s_{6} \times\left(1-g_{6}\right) \times h_{6} \times h_{26}$ & 0 \\
$s_{6} \times\left(1-g_{6}\right) \times\left(1-h_{2,6}\right) \times h_{6}$ & $s_{7} \times h_{7} \times h_{2,7}$ \\
$s_{6} \times\left(1-g_{6}\right) \times\left(1-h_{6}\right)$ & $s_{7} \times\left(1-h_{2,7}\right) \times h_{7}$ \\
$s_{6} \times g_{6}$ & $s_{7} \times\left(1-h_{7}\right)$ \\
\hline
\end{tabular}

tion. For these estimates, we grouped data across all plots within a population. Separate likelihood ratio chisquare $(G)$ tests for each of the five site by annual transition combinations (estimated with all zero frequency cells defined as structural zeros in increasing power) showed significant plot effects on transition probabilities only for the Medes population from 20022003 ( $P=0.012)$. We also used $G$ tests to check the assumption that demographic rates can be modeled as first-order Markov processes (Caswell 2001) and found no significant second-order effects for either population.

With the classes we used, the median and minimum number of colonies starting each transition in each year were 99 and 16, respectively, giving reasonable sample sizes for vital rate estimation (the minimum number of colonies were all for size class 2 , newly found colonies). As a check, we also used logistic regression to estimate survival as a continuous function of size (log likelihood $-2 \mathrm{LL}=793.434$, chi square $=33.788, \mathrm{df}=3, P<0.001)$; this resulted in survival estimates extremely similar to those found with direct estimation. Since no data are available on the demographic rates for yearling (primary) polyps due to the difficulty of detecting them in the field, we made the optimistic assumption that their survival is equal to that of size class 2 and that all surviving class 1 polyps advance to class 2 . Preliminary analyses indicated that alterations of this assumption had no important effects on our results.

To estimate reproduction, we used the relationship between the colony size and the gonadal production described in a previous study of this species (Coma et al. $1995 b$ ). Based on these data, we assume that the reproductive term $f_{i}$ can be estimated as the product of (1) the size-dependent gonadal production of oocytes from female colonies (assuming a 1:1 sex ratio; Coma et al. 1995a); (2) the fecundity of the gonads (fraction of gonads converted to eggs (C. Linares, unpublished data); and (3) the annual survival rate from eggs to primary polyps that would be seen during the census just before the reproductive pulse in June (C. Linares, unpublished data). (Note that we do not include a correction of onehalf in this estimation of $f$ to account for dioecy; while only half of colonies are female, our model is for the entire population of male and female colonies, such that the halving of colony number to estimate the number of female colonies is offset by the doubling of reproduction to account for male offspring.) The resulting sizedependent estimates of total production of class 1 polyp were then used in each matrix estimated, but did not vary with population or year.

From these vital rate estimates we constructed transition matrices for each time interval for each population (see Appendix A) and a mean matrix for each population. We calculated several outputs from these matrix models. First, we determined the long-term deterministic growth rate, $\lambda_{1}$, predicted by each matrix. Second, we calculated the damping ratio for each matrix, $\rho=\lambda_{1} /\left|\lambda_{2}\right|$ (Caswell 2001), which provides a measure of how fast a population will converge to the stable stage distribution. Third, we quantified patterns of importance to $\lambda_{1}$ of changes in each vital rate for the mean matrix for each population; given that there is no single correct scaling for measures of relative importance of different vital rates (Caswell 2001, Morris and Doak 2002), we present both sensitivity and elasticity values as measures of importance. Finally, we asked how size structure will develop following population establishment, a critical question in interpreting observed population structures. To explore the development of a newly founded population, we used the mean matrix of each population to simulate 100 years of population growth, starting with 100 colonies of class 1 polyp. At each time step the size distribution was recorded, and the results were compared with the observed distribution of each site. To compare the observed and predicted size distributions, the class 1 (primary polyps) were not used, since this class is not observable in the field.

We also conducted a series of stochastic analyses. First, we estimated the stochastic population growth rate, $\lambda_{\mathrm{S}}$ for each population using equally likely random draws of our annual matrices. These random-draw simulations were also used to estimate the probabilities of quasi-extinction for each population for up to 150 years, using an extinction threshold of $10 \%$ of the initial population size and starting with a population size of 300 at stable stage distribution. Second, we used annual estimates of each vital rate to calculate the temporal means, variances, and covariances of vital rates and used Tuljapurkar's small noise approximation to calculate stochastic sensitivity and elasticity values (Tuljapurkar 1990; programs from Morris and Doak 2002 and Doak et al. 2005).

Finally, we employed the equations of Cochran and Ellner (1992) to calculate several different life history parameters for our mean matrices that are useful descriptors of longevity. Using their formulas we estimated the survivorship function $l_{x}$, which gives the probability that a newborn will survive to age $x$ (Cochran and Ellner [1992]: Eq. 2); the conditional total life span for newborn colonies, which is the mean age at death for a colony, given that they survive long enough to enter size class $i$ (Cochran and Ellner [1992]: Eq. 6); and the mean age of residence in each size class, which provides a method for relating the 

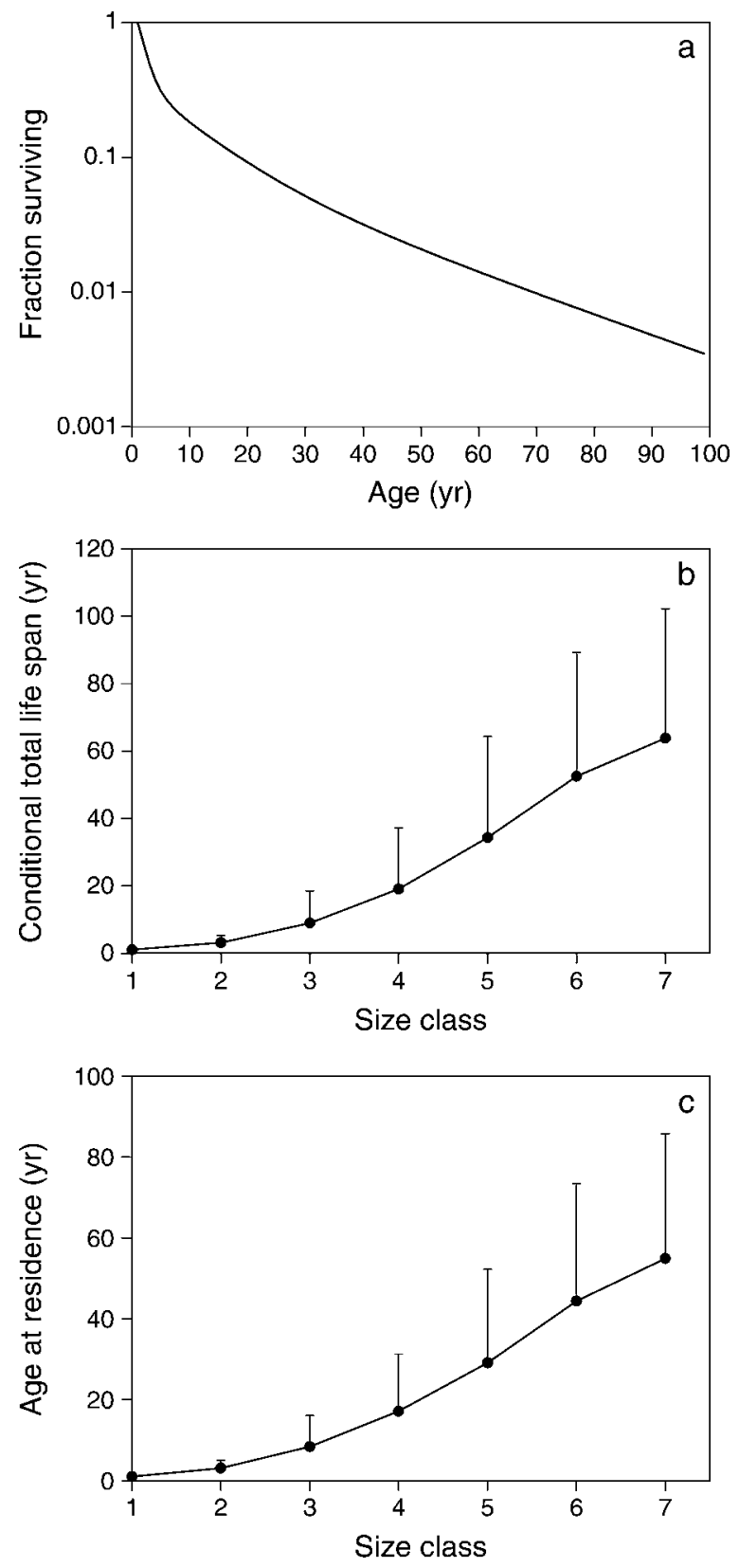

FIG. 1. (a) Survivorship curve (log scale) for newly established red gorgonian (Paramuricea clavata) colonies from Eq. 2 of Cochran and Ellner (1992). (b) Total estimated remaining life span, conditional on reaching a size class. (c) Age at residence or the age of individuals expected to be found in a size class for a population at stable stage distribution. The size classes correspond to the seven age and size stage classes defined in the model (see Methods: Model formulation for a thorough description of each class). Error bars representing one standard deviation, calculated using formulae of Cochran and Ellner (1992), are shown above each estimate. Red gorgonian populations were studied in the northwestern Mediterranean Sea. size and age of a given colony (Cochran and Ellner [1992]: Eq. 29). To estimate these parameters we used the survival matrix $\mathbf{P}$ from the mean matrix from each site and the birth matrix $\mathbf{B}$, which contains the reproductive values in the first rows and for which all other entries are zero (see Cochran and Ellner [1992] for details). These estimates were performed with the program STAGECOACH (Cochran and Ellner 1992).

We compared two life history patterns of red gorgonians obtained from our analyses with those of other sessile plants and animals. Following other studies (Silvertown et al. 1993, Franco and Silvertown 1996) we plotted expected life span (after the first year) against the summed elasticities of early life stage events (see Forbis and Doak [2004] for methods). For this comparison we gleaned data from the literature from demographic studies of sessile marine invertebrates and algae, terrestrial herbs, and terrestrial shrubs and trees (see Appendix B for species and data). We also contrasted the life span against the first age at sexual maturity with species for which we could glean the necessary data from the literature (see Appendix C for species and data).

\section{RESUlts}

\section{Life history and sensitivity analysis}

Our model results indicate that red gorgonians are long-lived. We found 63-97\% survival, with the lowest values for class 2 colonies and survival rising to $83-100 \%$ in the largest size class. The populations showed a mean survival rate of $\sim 91 \%$ and a mean recruitment rate of $\sim 3 \%$ (see Appendix D). In addition, growth rates were slow, with the medians of the probability of growing ranging from 0 to $41 \%$ across sizes and years. Just as strikingly, the probability of shrinking was higher than that of growing for many size classes in many years (see Appendices A and D).

Red gorgonian individuals followed a characteristic type III survivorship curve, with rapid declines in survivorship during the first years of life followed by slow and constant declines of large and old individuals and high longevity (Fig. 1a). Because survival of the smaller size classes was low, mean total life span from settlement was relatively short, but if colonies survived to reach the largest size class, they lived $>60 \mathrm{yr}$ (Fig. 1b). The high variance around each age-dependent life span estimate indicates that the fates of individual colonies are highly variable, with some colonies living considerably longer than the average. The mean age of residence in each class provided a direct way to examine the sizeage relationship. The mean age at residence increased progressively with size class, with a predicted value of $54.9 \mathrm{yr}$ for colonies in size 7 (Fig. 1c). As for total life span, the high variances in age at residence for larger sizes mean that some colonies will be far older than the mean and some far younger.

The sensitivities to mean vital rates estimated by deterministic and stochastic models were quite similar (Fig. 2a, b), indicating that the degree of variability in 

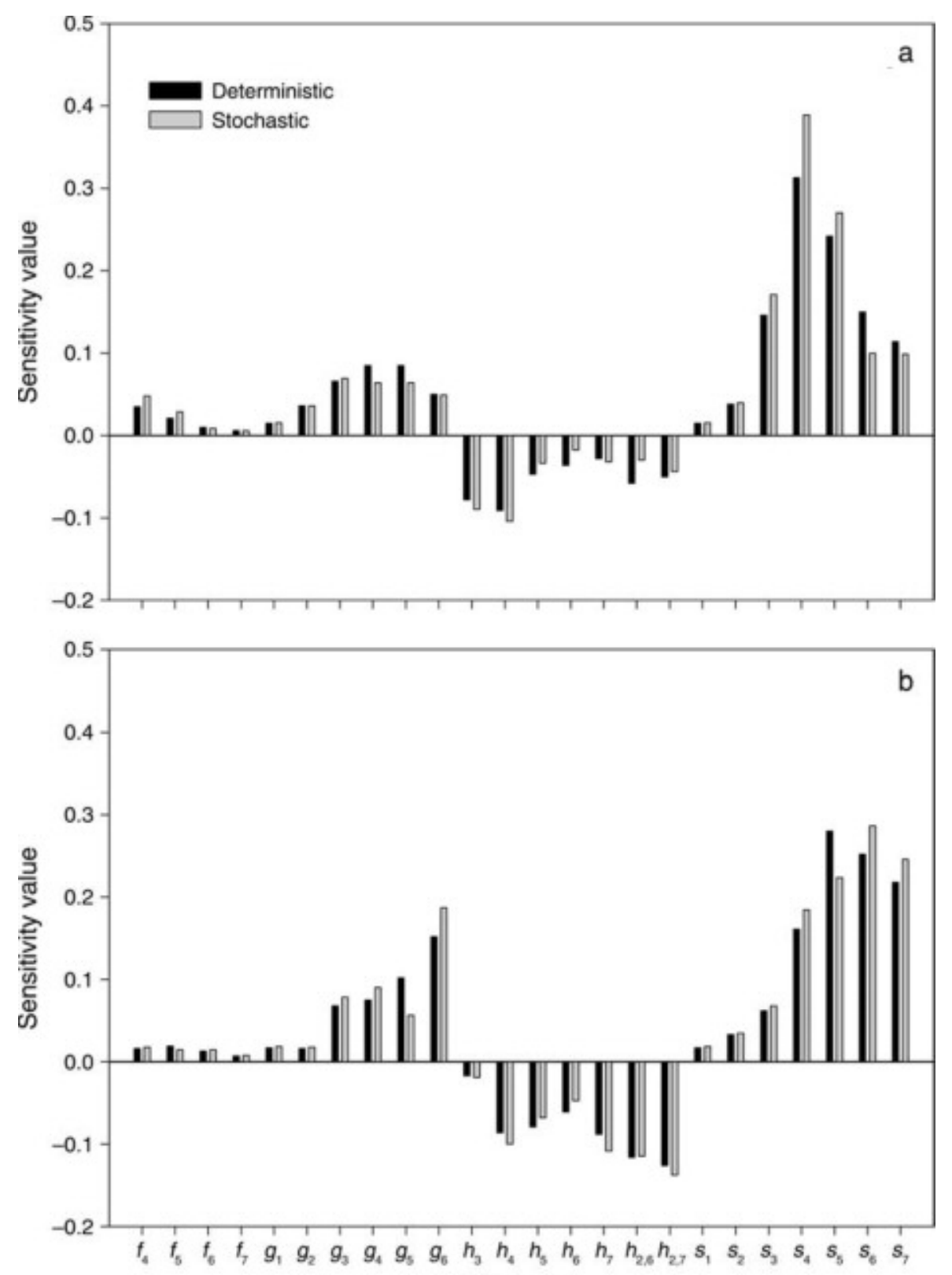

Vital rates

FIG. 2. Deterministic and stochastic sensitivities of red gorgonian population growth rate to mean vital rates for (a) Medes Island and (b) Cap de Creus populations. Abbreviations are: $f$, fecundity; $g$, growth; $h$, shrink into next smaller class; $h_{2}$, shrink into class two intervals smaller; $s$, survival. The numbers following the vital rates abbreviations indicate the respective size class for each vital rate.

demography observed over the study period was not particularly important for red gorgonian population dynamics. In addition, the sensitivities of $\lambda_{\mathrm{S}}$ to variances and covariances of vital rates were small (results not shown); consequently, we present only the deterministic elasticity results. Elasticities showed a similar, but stronger, pattern to that of the sensitivities, indicating that gorgonian population growth is far more sensitive to changes in survival rates than to growth, shrink, or reproductive rates (Fig. 3). The survivorship of the largest colonies (height $>40 \mathrm{~cm}$ ) did not have the highest elasticity values at either site, due to the relative rarity of these largest individuals. For the Medes Islands, the elasticity of survival rates for class 4 and 5 had the largest values, while in Cap de Creus, the highest elasticities were for survival of classes 5 and 6 . The elasticity analyses also suggested that the reproductive parameters (such as reproductive values and survival of newborns and recruits) contributed little to the rate of population increase over the examined period. 


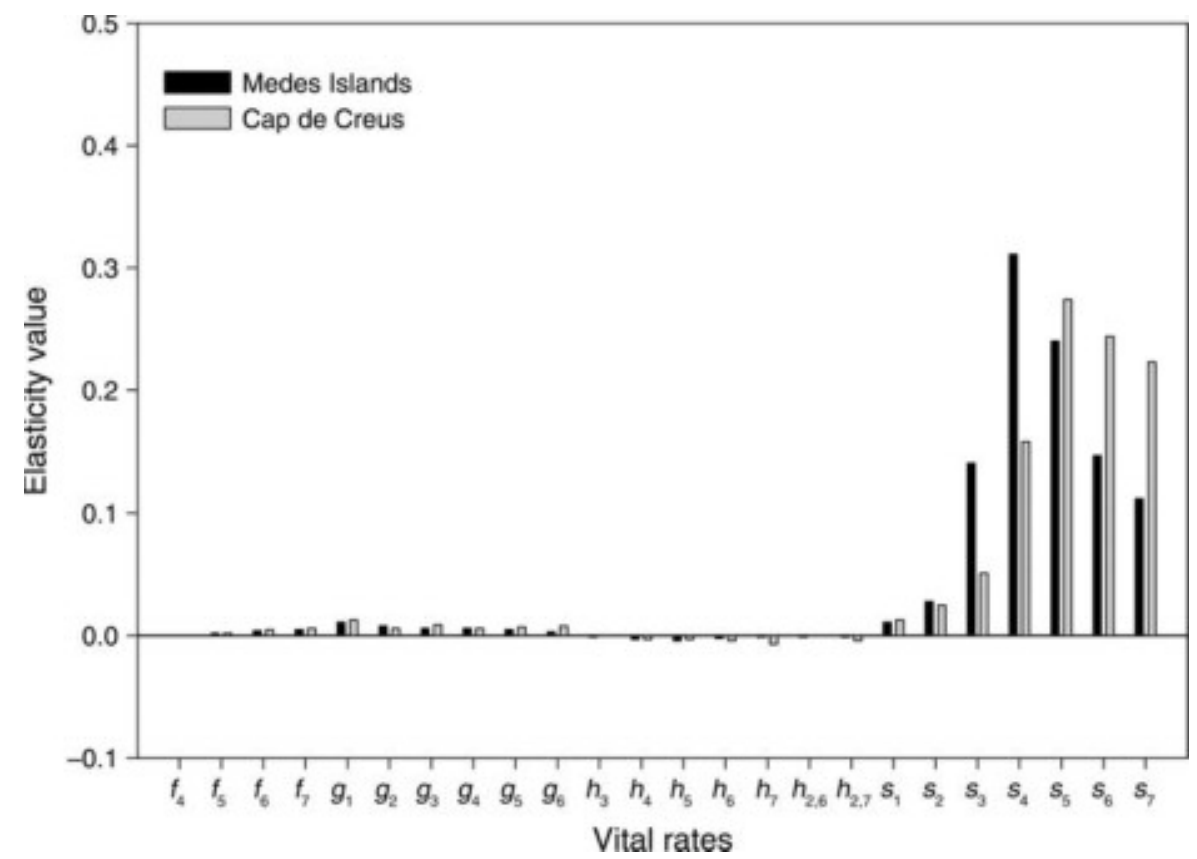

FIG. 3. Elasticity values of deterministic population growth rate for vital rates. Abbreviations are: $f$, fecundity; $g$, growth; $h$, shrink into next smaller class; $h_{2}$, shrink into class two intervals smaller; $s$, survival. The subscripts of the vital rates indicate the respective size class for each vital rate.

\section{Population growth and stage structure}

The annual multiplication rate associated with the different site and time matrices varied considerably (Table 2), but all matrices predicted declines in gorgonian populations $(\lambda<1)$. Notably, $\lambda_{1}$ values for the two mean matrices were almost identical to $\lambda_{\mathrm{S}}$ values for the populations, again indicating the extremely small effects of environmental stochasticity. $\lambda_{1}$ values were generally lower for the Medes Islands population than for gorgonians at Cap de Creus. With $\lambda_{\mathrm{S}}$ values $<1$, long-term extinction is inevitable, and our simulations suggested high risk of extinction over moderate time horizons (Fig. 4). Quasi-extinction risks correspond to the differences in $\lambda_{\mathrm{S}}$, with median extinction times of 41

TABLE 2. Annual multiplication rates $\left(\lambda_{1}\right.$, deterministic lambda; $\lambda_{\mathrm{S}}$, stochastic lambda) and damping ratios $(\rho)$ of transition matrices constructed from different sites and years.

\begin{tabular}{lccc}
\hline \hline \multicolumn{1}{c}{ Years } & $\lambda_{1}$ & $\lambda_{\mathrm{S}}$ & $\rho$ \\
\hline Medes Islands & & & \\
2001-2002 & 0.929 & & 1.1961 \\
2002-2003 & 0.988 & & 1.1289 \\
2003-2004 & 0.935 & & 1.0290 \\
Mean & 0.937 & 0.936 & 1.1244 \\
Cap de Creus & & & \\
2002-2003 & 0.996 & & 1.1409 \\
2003-2004 & 0.933 & & 1.0559 \\
Mean & 0.974 & 0.974 & 1.1496 \\
\hline
\end{tabular}

Note: Mean $\lambda_{1}$ values were estimated from the average matrix of the available transitions for each site. and $115 \mathrm{yr}$ at Medes Islands and Cap de Creus, respectively.

The damping ratios for all matrices were quite low, ranging from 1.02 to 1.19 , and indicating slow convergence to a stable size structure (Table 2). The simulated evolution of size distributions from recently established populations showed that the proportion in each size class slowly converges to a mean value (see Appendix E). In both sites an approximately stable stage distribution was obtained after $50 \mathrm{yr}$. The observed size distribution was quite similar at Medes Islands and Cap de Creus, showing a dominance of small reproductive colonies

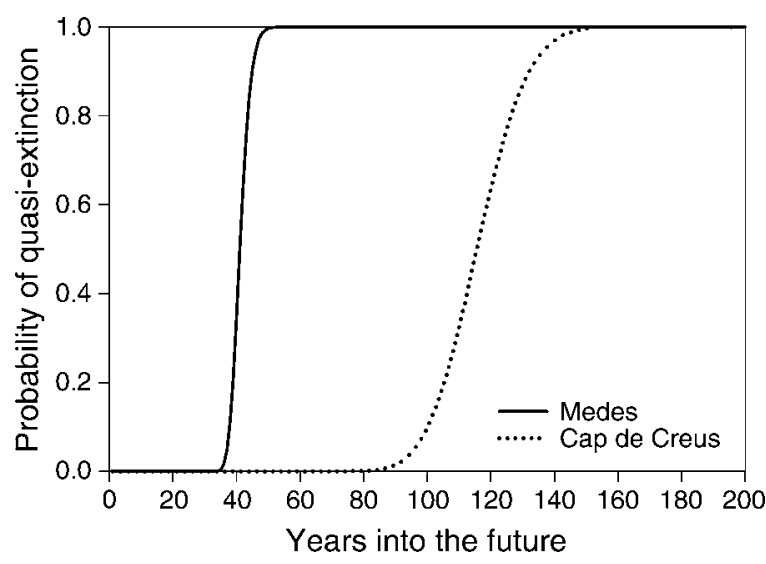

FIG. 4. Cumulative distribution function (CDF) for the time to reach a quasi-extinction threshold of $10 \%$ of initial population. For each population 50000 simulations were run. 
ranging from 10 to $20 \mathrm{~cm}$. The main difference between the sites was the greater proportion of large colonies $(>20 \mathrm{~cm})$ in Cap de Creus (see Appendix E). The observed stage distributions were not significantly different from the predicted stable stage distributions for either population (Medes Islands, KolmogorovSmirnov [K-S] test, $D=0.167, P>0.1$; Cap de Creus, $\mathrm{K}-\mathrm{S}$ test, $D=0.333, P>0.10$ ). Some differences can be observed, such as a small proportion in the smallest classes compared to that predicted for both populations and larger proportion of colonies in class 5 in the observed distribution than in the predicted one for the Cap de Creus site. Nonetheless, these size distributions indicate that the Medes Islands and the Cap de Creus populations are likely to have existed at least $50 \mathrm{yr}$.

\section{Comparative life history}

Across the species surveyed, there was a general decrease in reproductive elasticities with increasing life span. Relative to its life span, the red gorgonian shows a lower importance of reproductive vital rates than do other marine invertebrates (Fig. 5a). However, it falls within the expected range of long-lived trees and shrubs, species that share its basic morphology, if differing in all other aspects of their biology. In our second comparison, of age at sexual maturity vs. life span (Fig. 5b), red gorgonian again conforms to the relationship seen for trees, but has a late age at sexual maturity compared with the other marine invertebrate species.

\section{DisCUSSION}

While red gorgonians are important structural components of Mediterranean hard-bottom communities, we know little of the basic ecologic processes determining the resilience of these populations to natural and anthropogenic disturbances. Therefore, the first goal of this study was to quantify the life history and population viability of red gorgonians and to identify the life history traits to which population growth is most sensitive.

Red gorgonian populations show a life history pattern of high survival, low growth rates, and delayed onset of reproduction. Our estimates of the conditional total life span suggest that if colonies can attain the largest class they may be $60-100 \mathrm{yr}$ old. Unlike most demographic analyses of marine organisms (e.g., Hughes 1984, Gotelli 1991, Lasker 1991, McFadden 1991), we focused our sensitivity and elasticity analyses on the vital rates that correspond to demographic processes, not on the matrix elements that are combinations of these rates. As noted by other authors (Zudeima and Franco 2001, Franco and Silvertown 2004), vital rate elasticities are more informative than those for matrix elements because they correspond better to fundamental demographic processes (fecundity, growth, shrinkage, and survival). Our elasticity results suggest that population growth is overwhelmingly dependent on survival rates, principally of reproductive colonies $(>10 \mathrm{~cm})$. The differences observed between sites, with survival of larger colonies
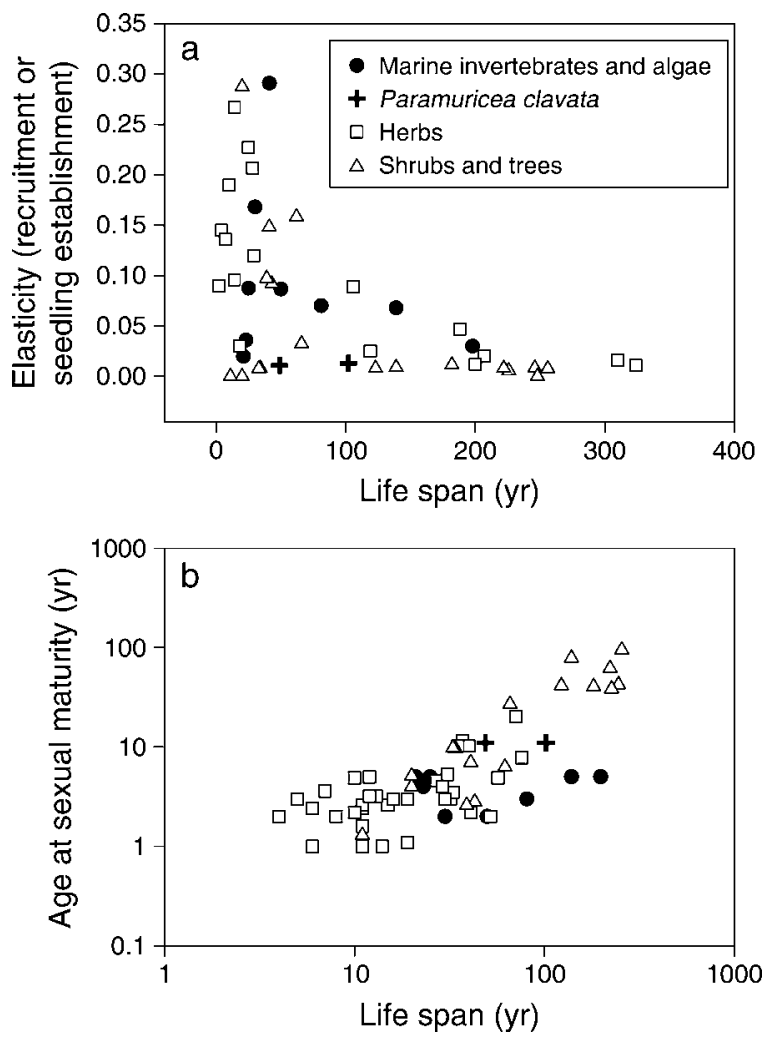

FIG. 5. (a) Comparison of elasticity values of recruitment or seedling establishment and life span (see Appendix B). (b) Loglog comparison of age at sexual maturity and life span of different marine species, herbs, shrubs, and trees (see Appendix C).

$(>20 \mathrm{~cm})$ in Cap de Creus showing higher elasticity values than those for the Medes Islands, are due to the different proportion of larger colonies $(>20 \mathrm{~cm})$ at the two sites (49\% and $42 \%$, respectively) and the higher survival rates of these larger colonies in Cap de Creus (see Appendix D). Red gorgonians thus conform to the generality that decreases in adult survival rate should more negatively effect population growth for long-lived species with low annual reproductive success than they will for short-lived and highly fecund species (Heppel et al. 2000).

In contrast to survival rates, population growth for the red gorgonian is little affected by recruitment variation, as has been found for other gorgonian species (Gotelli 1991, Lasker 1991). Recruitment has been considered widely as an important factor structuring marine communities, with high fecundity of many marine invertebrates combining with spatial and temporal patchiness in larval supply to generate spectacular recruitment pulses and crashes in local populations (Caffey 1985, Caley et al. 1996). In contrast to shortlived species, populations of some long-lived sessile species have been shown to be buffered against such fluctuations in recruitment, even when normally low yearly rates alternate with sporadic high peaks (Yoshioka 1996, Connell et al. 1997, Hughes and Tanner 2000, 
Garrabou and Harmelin 2002). Our results suggest that this pattern is comparable for red gorgonian. For such taxa, recruitment variation has limited importance, at least for local populations and relatively short time scales. Instead, survival of large colonies is a key factor for the population persistence, in part because they determine how long a population can persist without recruitment. Still, recruitment patterns may be more important over longer time scales, governing the establishment of new populations, in particular. While the patchy distribution of red gorgonian populations suggests that it may exist as a metapopulation, larger temporal and spatial scale surveys of the species are needed to investigate the role of recruitment in the dynamics of this long-lived organism.

One of the most striking results from our study is the similarity in life history traits between red gorgonians and terrestrial plants. For instance, the values of recruitment elasticity for Paramuricea clavata are lower than those reported for other marine organisms but are similar to those reported for long-lived plants (Silvertown et al. 1993, Morris and Doak 1998, Forbis and Doak 2004). Across species, fertility and recruitment elasticities are strongly correlated with age at maturation, mean fertility, generation time, and life expectancy. As described for other organisms (Heppell et al. 2000, Forbis and Doak 2004), populations with high mean adult survival rates generally have low fertility elasticities and higher adult survival elasticities. In particular, our data are consistent with the relationship between recruitment/seedling establishment elasticities and longevity seen for other species with similar life history traits such as herbs, shrubs, and trees (Forbis and Doak 2004, Franco and Silvertown 2004) pointing to the existence of a clear fecundity/mortality trade-off (Fig. 5a). This trade-off is also evident if we relate the life span with the age at maturation and we compare red gorgonian with other similar organisms such as plants (Fig. 5b). This result, comparable to that reported for other gorgonian species (Lasker 1990, Gotelli 1991, Yoshioka 1998, Garrabou and Harmelin 2002), is in concordance with the bet-hedging theory, which predicts adults are selected for high survival when recruitment is highly variable because a long reproductive life is needed to counterbalance years of high juvenile mortality (Stearns 1992).

We also used our demographic models to investigate current population structures and likely future population health. Our simulations show that populations need $\sim 50$ years to approach stable stage distributions and that the observed population structures are quite similar from predicted stable stage distributions at both sites. The main difference is due to the very few colonies in the first observable class, possibly a consequence of recent recruitment failures. Because anthropogenic changes in mortality rates are likely to be relatively size-independent, any changes in demographic rates due to these impacts probably have had little effect on size distribu- tions, also helping to explain the good match between our observed and predicted population stage structures.

Given the observed vital rates, both populations appear to be in decline, with both deterministic and stochastic growth rates less than one. The explanation for these declines is likely to be found in anthropogenic impacts. As noted above, while both study areas are located within marine protected areas, both are also heavily visited by divers. Other authors have described an increase in red gorgonian mortality rates in areas with high numbers of divers, caused by mechanical disturbances (Coma et al. 2004). The differences of the population growth rates in the studied areas also suggest the importance of the diving impact on the population decline. While both areas have substantial diving activity, the Medes Islands have higher visitation, possibly explaining the higher mortality and lower population growth rates at this study site. However, we have to be cautious about this explanation due to its correlative nature.

The fact that these populations were observed 30 years ago (M. Zabala, personal communication) with a similar distribution as observed now indicates a high persistence of these populations in a stable state. These results contrast with the decline and the extremely high extinction risk predicted by the model, but this apparent divergence may be explained by recent increases in mortality rates due to escalating anthropogenic disturbances. Better understanding of the general long-term patterns on gorgonian populations will require the study of other populations not affected by these kinds of perturbations.

The major limitation in our results comes from the relatively short time period of data collection. Temporal variability had little effect on population growth rates or sensitivity results over our study period. While recruitment variation is unlikely to substantially influence our results, infrequent mass mortality events have been observed in red gorgonian populations, and these pulses of mortality could substantially alter the size composition and dynamics we predict. Nonetheless, the model developed in this study allows us to better understand the demography of this species and the likely importance of different threats to population viability.

\section{ACKNOWLEDGMENTS}

Thanks to the people of the Doak lab for helpful discussions and above all, for a pleasant working environment. We are grateful to Joaquim Garrabou for the continuous encouragement. Support for this work was provided by a research grant (DURSI 2004 BE 00231) to C. Linares from the "Generalitat de Catalunya." This study was funded in part by the "Departament de Medi Natural" of the "Generalitat de Catalunya," by a research grant CTM2004-03120/MAR from the "Ministerio de Educación y Ciencia" of Spain to R. Coma, and by NSF DEB0087078 and USDA 2002-00610 to D. F. Doak.

\section{Literature Cited}

Babcock, R. C. 1991. Comparative demography of three species of scleractinian corals using age and size-dependent classifications. Ecological Monographs 61:225-244. 
Ballesteros, E. 2006. Mediterranean coralligenous assemblages: a synthesis of present knowledge. Oceanography and Marine Biology 44:123-195.

Bavestrello, G., and F. Boero. 1986. Necrosi e rigenerazione in Eunicella cavolinii in Mar Ligure. Bollettino dei Musei e degli Istituti Biologici dell'Universita di Genova 52:295-300.

Bavestrello, G., C. Cerrano, D. Zanzi, and R. Cattaneo-Vietti. 1997. Damage by fishing activities to the Gorgonian coral Paramuricea clavata in the Ligurian Sea. Aquatic Conservation: Marine and Freshwater Ecosystems 7:253-262.

Beissinger, S. R., and D. R. McCullough, editors. 2002. Population viability analysis. University of Chicago Press, Chicago, Illinois, USA.

Caffey, H. M. 1985. Spatial and temporal variation in settlement and recruitment of intertidal barnacles. Ecological Monographs 55:313-332.

Caley, M. J., M. H. Carr, M. A. Hixon, T. P. Hughes, G. P. Jones, and B. A. Menge. 1996. Recruitment and the local dynamics of open marine populations. Annual Review of Ecology and Systematics 27:477-500.

Caswell, H. 2001. Matrix population models: construction, analysis, and interpretation. Second edition. Sinauer, Sunderland, Massachusetts, USA.

Cerrano, C., et al. 2000. A catastrophic mass mortality episode of gorgonians and other organisms in the Ligurian Sea (NW Mediterranean), summer 1999. Ecology Letters 3:284-293.

Cochran, M. E., and S. Ellner. 1992. Simple methods for calculating age-based life history parameters for stagestructured populations. Ecological Monographs 62:345-364.

Coma, R., C. Linares, and E. Pola. 2003. Seguiment temporal de la gorgònia Paramuricea clavata de les illes Medes Exercici 2003. Pages 67-79 in M. Zabala, editor. Seguiment temporal de l'àrea marina protegida de les illes Medes. Informe anual any 2003. Departament de Medi ambient, Generalitat de Catalunya, Barcelona, Spain.

Coma, R., C. Linares, E. Pola, and M. Zabala. 2001. Seguiment temporal de la gorgònia Paramuricea clavata de les illes Medes Exercici 2001. Pages 59-82 in M. Zabala, editor. Seguiment temporal de l'àrea marina protegida de les illes Medes. Informe anual any 2001. Departament de Medi ambient, Generalitat de Catalunya, Barcelona, Spain.

Coma, R., E. Pola, M. Ribes, and M. Zabala. 2004. Long-term assessment of temperate octocoral mortality patterns, protected vs. unprotected areas. Ecological Applications 14: 1466-1478.

Coma, R., M. Ribes, M. Zabala, and J. M. Gili. 1995a. Reproduction and cycle of gonadal development in the Mediterranean gorgonian Paramuricea clavata. Marine Ecology Progress Series 117:173-183.

Coma, R., M. Ribes, M. Zabala, and J. M. Gili. 1998. Growth in a modular colonial marine invertebrate. Estuarine, Coastal and Shelf Science 47:459-470.

Coma, R., M. Zabala, and J. M. Gili. 1995b. Sexual reproductive effort in the Mediterranean gorgonian Paramuricea clavata. Marine Ecology Progress Series 117:173183.

Connell, J. H., T. P. Hughes, and C. C. Wallace. 1997. A 30year study of coral abundance, recruitment, and disturbance at several scales in space and time. Ecological Monographs 67:461-488.

Cook, R. E. 1985. Growth and development in clonal plant populations. Pages 259-296 in J. B. C. Jackson, L. W. Buss, and R. E. Cook, editors. Population biology and evolution of clonal organisms. Yale University Press, New Haven, Connecticut, USA.

Crowder, L. B., D. T. Crouse, S. S. Heppell, and T. H. Martin. 1994. Predicting the impact of turtle excluder devices on loggerhead sea turtle populations. Ecological Applications 4: 437-445.

Doak, D. F., W. F. Morris, C. Pfister, B. E. Kendall, and E. M. Bruna. 2005. Correctly estimating how environmental stochasticity influences fitness and population growth. American Naturalist 166:E14-E21.

Doak, D. F., D. M. Thomson, and E. S. Jules. 2002. PVA for plants: understanding the demographic consequences of seed banks for population health. Pages $312-337$ in S. R. Beissinger and D. R. McCullough, editors. Population viability analysis. University of Chicago Press, Chicago, Illinois, USA.

Done, T. J. 1988. Simulation of recovery of pre-disturbance size structure in populations of Porites spp. damaged by the crown of thorns starfish Acanthaster planci. Marine Biology 100:51-61.

Forbis, T. A., and D. F. Doak. 2004. Seedling establishment and life history trade-offs in alpine plants. American Journal of Botany 91:1147-1153.

Franco, M., and J. Silvertown. 1996. Life history variation in plants: an exploration of the fast-slow continuum hypothesis. Philosophical Transactions of the Royal Society of London B 351:1341-1348.

Franco, M., and J. Silvertown. 2004. A comparative demography of plants based upon elasticities of vital rates. Ecology 85:531-538.

Garrabou, J., and J. G. Harmelin. 2002. A 20-year study on life-history traits of a harvested long-lived temperate coral in the NW Mediterranean: insights into conservation and management needs. Journal of Animal Ecology 71:966-978.

Gerber, L. R., and S. Heppell. 2004. The use of demographic sensitivity analysis in marine species conservation planning. Biological Conservation 120:121-128.

Gotelli, N. J. 1991. Demographic models for Leptogorgia virgulata, a shallow-water gorgonian. Ecology 72:457-467.

Heppell, S. S., H. Caswell, and L. B. Crowder. 2000. Life histories and elasticities patterns: perturbation analysis for species with minimal demographic data. Ecology 81:654-665.

Holmes, E. E., and A. E. York. 2003. Using age structure to detect impacts on threatened populations: a case study with steller sea lions. Conservation Biology 17:1794-1806.

Hughes, T. P. 1984. Population dynamics based on individual size rather than age: a general model with a reef coral example. American Naturalist 123:778-795.

Hughes, T. P. 1990. Recruitment limitation, mortality and population regulation in open systems: a case study. Ecology 71:12-20.

Hughes, T. P., and J. B. C. Jackson. 1985. Population dynamics and life histories of foliaceous corals. Ecological Monographs 55:141-166.

Hughes, T. P., and J. E. Tanner. 2000. Recruitment failure, life histories and long-term decline of Caribbean corals. Ecology 81:2250-2263.

Jones, C. J., J. H. Lawton, and M. Shachak. 1994. Organisms as ecosystem engineers. Oikos 69:373-386.

Lasker, H. R. 1990. Clonal propagation and population dynamics of a gorgonian coral. Ecology 71:1578-1589.

Lasker, H. R. 1991. Population growth of a gorgonian coral: equilibrium and non-equilibrium sensitivity to changes in life history variables. Oecologia 86:503-509.

Linares, C., R. Coma, D. Díaz, M. Zabala, B. Hereu, and L. Dantart. 2005. Immediate and delayed effects of a mass mortality event on gorgonian population dynamics and benthic community structure in the NW Mediterranean. Marine Ecology Progress Series 305:127-137.

McFadden, C. S. 1991. A comparative demographic analysis of clonal reproduction in a temperate soft coral. Ecology 72: 1849-1866.

Morris, W. F., and D. F. Doak. 1998. Life history of the longlived gynodioecious cushion plant, Silene acaulis (Caryophyllaceae), inferred from size-based population projection matrices. American Journal of Botany 85:784-793.

Morris, W. F., and D. F. Doak. 2002. Quantitative conservation biology: theory and practice of population viability analysis. Sinauer, Sunderland, Massachusetts, USA. 
Nakaoka, M. 1993. Yearly variation in recruitment and its effects on population-dynamics in Yoldia notabilis (Mollusca, Bivalvia), analyzed using projection matrix model. Researches on Population Ecology 35:199-213.

Nakaoka, M. 1997. Demography of the marine bivalve Yoldia notabilis in fluctuating environments: an analysis using a stochastic matrix model. Oikos 79:59-68.

Perez, T., J. Garrabou, S. Sartoretto, J. G. Harmelin, P. Francour, and J. Vacelet. 2000. Mortalité massive d'invertébrés marins: un événement sans précédent en Méditerraneé nord-occidentale. Comptes Rendus de l'Académie des Sciences Serie III 323:853-865.

Pfister, C. A., and A. Bradbury. 1996. Harvesting red sea urchins: recent effects and future predictions. Ecological Applications 6:298-310.

Silvertown, J., M. Franco, and E. Menges. 1996. Interpretation of elasticity matrices as an aid to the management of plant populations for conservation. Conservation Biology 10:591597.

Silvertown, J., M. Franco, I. Pisanty, and A. Mendoza. 1993. Comparative plant demography: relative importance of lifecycle components to the finite rate of increase in woody and herbaceous perennials. Journal of Ecology 81:465-476.

Stearns, S. C. 1992. The evolution of life histories. Oxford University Press, Oxford, UK.

Thompson, P. M., B. Wilson, K. Grellier, and P. S. Hammond. 2000. Combining power analysis and population viability analysis to compare traditional and precautionary approaches to conservation of coastal cetaceans. Conservation Biology 14:1253-1263.

True, M. A. 1970. Étude quantitative de quatre peuplements sciaphiles sur substrat rocheux dans la région marseillaise. Bulletin de L'Institute Océanographique du Monaco 1410:148.

Tuljapurkar, S. 1990. Population dynamics in variable environments. Lecture notes in Biomathematics 85. Springer, New York, New York, USA.

Weinberg, S. 1991. Faut-il proteger les gorgones de Méditerraneé? Pages 47-52 in C. F. Boudouresque, M. Avonb, and V. Gravez, editors. Les Espèces à Protéger en Méditerraneé. GIS Posidonie, Marseille, France.

Yoshioka, P. M. 1994. Size-specific life history pattern of shallow-water gorgonian. Journal of Experimental Marine Biology and Ecology 184:111-122.

Yoshioka, P. M. 1996. Variable recruitment and its effect on the population and community structure of shallow-water gorgonians. Bulletin of Marine Science 59:433-443.

Yoshioka, P. M. 1998. Are large colonies a "key factor" in the dynamics of gorgonian populations? Revista de Biologia Tropical 46:137-143.

Zuidema, P. A., and M. Franco. 2001. Integrating vital rate variability into perturbation analysis: an evaluation for matrix population models of six plant species. Journal of Ecology 89:995-1005.

\section{APPENDIX A}

Size class transition matrices for Paramuricea clavata populations at Medes Islands and Cap de Creus (Ecological Archives E088057-A1).

\section{APPENDIX B}

A table showing the relation between life span and elasticity of recruitment $\left(E_{\mathrm{rec}}\right)$ (Ecological Archives E088-057-A2).

\section{APPENDIX C}

A table showing the relation between life span and age at sexual maturity (Ecological Archives E088-057-A3).

\section{APPENDIX D}

A table showing vital rates of Paramuricea clavata populations at Medes Island and Cap de Creus over the study period (Ecological Archives E088-057-A4).

\section{APPENDIX E}

Graphs of the observed size frequency distributions of colonies and predicted size distributions of two populations of Paramuricea clavata, at Medes Islands and Cap de Creus (Ecological Archives E088-057-A5). 